\title{
The causes of educational differences in fertility in sub-Saharan
} Africa

John Bongaarts

Population Council

Follow this and additional works at: https://knowledgecommons.popcouncil.org/departments_sbsr-pgy

Part of the Demography, Population, and Ecology Commons, Family, Life Course, and Society Commons, and the International Public Health Commons How does access to this work benefit you? Let us know!

\section{Recommended Citation}

Bongaarts, John. 2010. "The causes of educational differences in fertility in sub-Saharan Africa," Poverty, Gender, and Youth Working Paper no. 20. New York: Population Council. Version of record: https://doi.org/ 10.1553/populationyearbook2010s31 


\title{
POVERTY, GENDER, AND YOUTH
}

The Causes of Educational Differences in Fertility in sub-Saharan Africa

\author{
John Bongaarts
}

WORKING PAPER NO. $20 \quad 2010$

$\mathcal{A}$ Population Council 


\section{(2) Population Council}

One Dag Hammarskjold Plaza

New York, New York 10017 USA

www.popcouncil.org

pubinfo@popcouncil.org

For information on Poverty, Gender, and Youth working papers, see www.popcouncil.org/publications/wp/index.html

This material may not be reproduced without written permission from the author.

ISSN: 1554-8538

(C) 2010 The Population Council, Inc. 


\title{
The Causes of Educational Differences in Fertility in sub-Saharan Africa
}

\author{
John Bongaarts
}

John Bongaarts is Vice President and Distinguished Scholar, Population Council, New York.

The author gratefully acknowledges support for this research from the William and Flora Hewlett Foundation. 


\begin{abstract}
This study first presents an analytic framework that describes the chain of causation linking fertility to its multiple layers of determinants. Next, this framework is applied to analyze the causes of educational fertility differences in 30 sub-Saharan African countries using data from DHS surveys. The results demonstrate that education levels are positively associated with demand for and use of contraception and negatively associated with fertility and desired family size. In addition, there are differences by level of education in the relationships between indicators. As education rises, fertility is lower at a given level of contraceptive use, contraceptive use is higher at a given level of demand, and demand is higher at a given level of desired family size. The most plausible explanations for these shifting relationships are that better-educated women marry later and less often, use contraception more effectively, have more knowledge about and access to contraception, have greater autonomy in reproductive decisionmaking, and are more motivated to implement demand because of the higher opportunity costs of unintended childbearing.
\end{abstract}


Until the 1970s fertility in sub-Saharan Africa remained high with an average total fertility rate around 6.7 births per woman, and differences between regions and countries were modest. Over the past quarter century, however, significant fertility declines have occurred particularly in Eastern and Southern Africa, while fertility remains near high pre-transitional levels in many countries in Western and Middle Africa. As a result, differences between countries have grown large over time. The total fertility rates of individual countries in 2000-05 ranged from a high of 7 births per woman in Niger to below 3 in South Africa (United Nations 2007).

In addition, substantial differences in reproductive behavior exist between socioeconomic groups within countries. Fertility is usually higher in rural than in urban areas, higher among the uneducated than among better-educated women, and higher in households with low rather than high incomes (Merrick 2001; Singh and Casterline 1985; Rutstein 2002; United Nations 1987). Educational differentials are among the best established and most widely studied (Cochrane 1979; Caldwell 1982; United Nations 1987, 1995; Cleland and Rodriguez 1988; Jejeebhoy 1995; Jeffery and Basu 1996; National Research Council 1999). According to Jejeebhoy (1995) women's education influences reproductive behavior through five types of autonomy: knowledge, decisionmaking, physical (ability to move freely outside the home), emotional, and economic and social. The effects of years of schooling remain significant after controlling for many other socioeconomic and behavioral factors (United Nations 1987; Cleland and Rodriguez 1988; Rodriguez and Aravena 1991; Castro Martín and Juárez 1995; United Nations 1995).

After noting sources of data, this study presents an analytic framework that describes the chain of causation linking fertility to its multiple layers of determinants, including use of and demand for contraception, desired family size, and level of socioeconomic development (including education). Next, this framework is used to examine and explain the causes of fertility differences by level of female education. The hypothesis is that higher levels of female education are associated with lower levels of fertility, unmet need for contraception, and desired family size and with higher levels of demand for and use of contraception. These results should shed light on the impact on reproductive behavior that can be expected from raising education levels among women.

\section{DATA}

The primary sources of data for this study are the latest available Demographic and Health Surveys conducted over the past decade in 30 countries $^{1}$ : Benin, Burkina Faso, Cameroon, Chad, Congo (Braz.), Congo Dem Rep., Côte d'Ivoire, Ethiopia, Gabon, Ghana, Guinea, Kenya, Lesotho, Liberia, Madagascar, Malawi, Mali, Mozambique, Namibia, Niger, Nigeria, Rwanda, Senegal, South Africa, Swaziland, Tanzania, Togo, Uganda, Zambia, and Zimbabwe.

To document and analyze relationships between different dimensions of reproductive behavior, five indicators are examined below:

Fertility as measured by the total fertility rate in the three years before the survey (TFR),

Contraceptive use as measured by the prevalence rate of all methods among currently married women (U), 
Demand for contraception (spacing or limiting) among currently married women (D),

The percent of this demand that is satisfied, estimated as U/D,

Reproductive preferences as measured by desired family size.

Estimates of these indicators (aggregate and by level of education) are taken from DHS first country reports (www.measuredhs.com) or calculated from the data tapes. Following standard DHS practice three education categories are used: no schooling, primary, and secondary + , based on country-specific definitions of primary and secondary schooling.

\section{ANALYTiC FrameWORK}

The empirical analysis of the causes of fertility differences is guided by the analytic framework depicted in Figure 1. This framework summarizes the main factors that determine fertility and the chain of causation that links layers of determinants. Socioeconomic development (e.g., rising level of education) is considered the main cause of a decline in the benefits of children and a rise in their costs that occur over the course of a fertility transition. These changes in the cost/benefit ratio lead parents to want fewer children, and mortality decline raises child survival so that families need fewer births to achieve the desired number of surviving children. These trends in turn raise the demand for birth control (i.e., contraception and induced abortion), and, to the extent this demand is satisfied, lower fertility results. Family planning programs facilitate this transition by reducing the cost of birth control (broadly defined to include social costs), thus raising implementation of the demand for contraception and reducing the unmet need for contraception. Family planning programs can also change parental perceptions of the costs and benefits of childbearing (e.g., through communication campaigns that emphasize the benefits of smaller families), thereby contributing to declines in fertility preferences.

A full analysis of this framework will not be attempted here in part because DHS surveys do not collect information on the costs and benefits of children and the cost of birth control. Instead the focus will be on selected variables, starting with fertility and contraceptive prevalence, followed by the demand for contraception and family size preferences, as well as the links between them.

\section{Aggregate Results}

Table 1 presents estimates of the four key indicators for each of the 30 countries included in this study. Differences among countries are large, with the following low-high ranges:

Total fertility rate (births per woman): from 2.9 in South Africa to 7.0 in Niger

Contraceptive prevalence (percent): from 2.8 in Chad to 60.2 in Zimbabwe

Demand for contraception (percent): from 23.5 in Chad to 74.7 in Swaziland

Desired family size (births per woman): from 2.3 in Swaziland to 8.6 in Chad.

According to the analytic framework these variables are causally related through successive links between layers of determinants. Each of the links relating desired fertility to actual fertility in Figure 1 will now be examined. 


\section{Effect of contraceptive use on fertility}

Previous studies have found a strong inverse correlation between the TFR and contraceptive prevalence (Ross et al. 2005; United Nations 2001). In pre-transitional societies fertility is high and deliberate use of contraception is rare, while in countries at the end of their transition fertility is low and the large majority of couples practice some form of contraception. This correlation between contraceptive prevalence and fertility is confirmed in Figure 2, which plots the relationship between TFR and contraceptive prevalence (among women in union) for the 30 countries included in this study.

This relationship is statistically significant $\left(\mathrm{R}^{2}=0.57\right)$, but individual countries deviate from the best-fitting regression line. This result may be attributable to measurement error, but another plausible partial explanation is related to the role of other proximate determinants. Fertility is directly determined by a set of behavioral and biological variables called the proximate determinants (Bongaarts and Potter 1983). Contraceptive use is one the most important of these, but there are a number of others, including proportions married or in union, contraceptive effectiveness, incidence of induced abortion, duration of postpartum infecundability, and frequency of intercourse. Over the course of the fertility transition changes occur in these other proximate determinants, with some having negative effects on fertility (e.g., increasing age at marriage) and others having positive effects (e.g., declines in the duration of postpartum infecundability). These effects usually offset one another at least partially, and their net impact is usually relatively small compared with the effect of rising contraceptive prevalence (Bongaarts and Potter 1983). However, the net effect of these other factors is not zero, hence deviations from the regression line in Figure 2 are not surprising. A full analysis of the effects of these other proximate determinants will not be attempted here.

\section{Effect of demand for contraception on use of contraception}

The level of demand for contraception is one of the main direct determinants of contraceptive use. In DHS reports the demand for contraception is measured as the level of contraceptive use that would prevail if every fecund woman who wants no more pregnancies is currently using contraception. Figure 3 plots use and demand for the 30 countries. ${ }^{2}$ The correlation is again strong with $\mathrm{R}^{2}=0.82$. Demand for (or potential use of) contraception is higher than the level of prevalence (or actual use) in all 30 countries. This difference implies a significant unmet demand/need for contraception (Bankole and Westoff 1995; Casterline and Sinding 2000; Westoff 2001). This issue will be discussed in more detail below.

\section{Effect of desired family size on the demand for contraception}

Reproductive preferences are the next link in the chain of causal factors that determine fertility. The DHS collects data for a number of preference measures including ideal family size, wanted total fertility rate, wanted/mistimed status of the most recent birth, and the proportion of women who want to space or limit childbearing. The present analysis relies mainly on desired family size because it is the most widely used preference measure. The key concern with this indicator is that older women may inflate their stated desired family size to be in accord with the number of children they already have, which may include unwanted births ("rationalization"). To 
minimize this potential error, the desired family size among women aged 20 to 29 will be used here as the indicator of fertility preferences.

Figure 4 plots the relationship between demand for contraception and average desired family size. There is a strong inverse correlation between these variables $\left(R^{2}=0.79\right)$ : the lower the desired family size, the larger the demand for contraception, which is as expected because contraception is the main means by which women implement their preferences for smaller families.

\section{Unmet need for contraception and unwanted fertility}

The preceding results are all in accordance with expectations from the analytic framework: the lower the desired family size, the higher the demand for and use of contraception and hence the lower fertility. However, the analytic framework does not predict levels of unmet need for contraception and how they might differ among countries.

As seen in Figure 3, levels of demand always exceed observed contraceptive use. Couples whose demand is not satisfied have an "unmet need" for contraception. The key cause of this unmet need is that contraception is often quite costly to individuals in terms of the commodities, transportation, and reimbursement of providers of contraceptives and health care services, even when subsidies are provided by the government. In addition, there are significant non-economic costs such as the fear of side effects, social disapproval, and spousal resistance, as well as unnecessary medical barriers (Casterline and Sinding 2000).

Figure 5 plots country-specific levels of unmet need for contraception as a function of the demand for contraception. This relationship has an inverted U-shape: unmet need is highest in countries with intermediate demand and lowest in countries with low and high demand. This pattern is the result of offsetting trends as countries move through the transition (Bongaarts 1997). In pre-transitional countries unmet need (and demand) is low because desired family size is high, and couples need most of their reproductive years to achieve a large family. Next, in the early stages of the transition, unmet need rises as desired family size declines, but the use of contraception lags behind the rise in demand. After peaking in mid-transition, unmet need declines in the last phases of the transition as the use (and effectiveness) of contraception catches up with demand and the cost of unwanted childbearing rises.

These trends suggest that the proportion of demand that is satisfied rises as countries move through the fertility transition. This conclusion is confirmed in Figure 6, which shows that as demand rises, the proportion using contraception among women with a demand also rises. For example, in Chad contraceptive demand is just 23 percent and the proportion of this demand that is satisfied is only 12 percent As a result contraceptive prevalence is 2.8 percent (12 percent of 23 percent), which is the lowest level observed in this set of countries. At the other end of the spectrum is Zimbabwe, where demand is 74 percent and satisfaction is 82 percent, thus yielding contraceptive prevalence of 60 percent. The level of satisfaction is a useful indicator of the extent to which women have ready access to quality family planning services and their ability to overcome various economic and social obstacles to using contraception.

An unmet need for contraception results in unwanted fertility, which, as shown in Figure 7, also exhibits a weak inverted U-shaped pattern. The explanation is broadly the same as for 
unmet need. Early in the fertility transition demand for contraception is low, which keeps both unmet need and unwanted fertility relatively low. For example, unwanted fertility is just 0.2 births per woman in Niger and Chad. In mid-transition unwanted fertility is generally highest (e.g., 1.9 births per woman in Swaziland). And at the end of the fertility transition unwanted fertility is relative low again (e.g., 0.6 births per woman in South Africa). In countries in Asia and Latin America that have reached replacement-level fertility, unwanted fertility is typically still lower, and it is reasonable to assume that unwanted fertility will decline further as countries in sub-Saharan Africa reach the end of their fertility transitions in future decades.

\section{EDUCATIONAL DIFFERENCES IN REPRODUCTIVE INDICATORS}

The preceding section examined differences in country-level indicators. The analysis will now be expanded to investigate educational differences within countries using the same indicators.

\section{Regional averages}

As a first step, averages across all 30 sub-Saharan countries (unweighted) are calculated for each of the reproductive indicators by level of education. Figure 8 plots the average TFR and desired family size. Women with secondary or higher education have on average lower fertility than women with no education (3.4 vs. 6.3 births per woman), and the same is true for desired family size (3.7 vs. 5.6 births per woman). Figure 9 plots the averages of contraceptive use and demand for contraception by level of education. ${ }^{3}$ Both indicators are positively associated with level of education. The gap between demand and use (unmet need) is lowest among the most highly educated women.

These relationships are as expected, but there is one surprising result in Figure 8: desired family size exceeds TFR among women with secondary or higher education (3.7 vs. 3.4 births per woman). This finding implies that a proportion of highly educated women do not reach their desired family size. This effect is even larger than suggested by the difference between desired family size and TFR because some births are unwanted. A comparison of the wanted TFR with desired family size indicates that the former falls short of the latter by a sizable 0.82 births for women with secondary and higher education. In contrast, the wanted TFR is very close to the desired family size in groups with lower levels of education. Plausible reasons for this outcome are that highly educated women face greater obstacles in trying to implement their childbearing preferences. Such obstacles may be economic (high direct and opportunity costs of children), social (inability to find a suitable partner, late marriage, desire for a lifestyle or career incompatible with childbearing), or biological (risk of infertility at higher age).

\section{Country-level analysis}

The decline in desired family size and the rise in demand for and use of contraception with rising levels of education evident in Figures 8 and 9 are observed in each of the 30 countries. The negative association between the TFR and education level is almost as robust. The TFR among women with secondary and higher education is lower than for women with primary education in all 30 countries, and the TFR of women with primary education is lower than for 
women with no education in 27 countries. The exceptions are Chad, Congo (Brazaville), and DR Congo, where fertility is highest among women with primary education. The explanation for these exceptions will not be pursued here but probably lies in the proximate determinants other than contraception (e.g., lower frequency of intercourse due to spousal separation among women with no education). In addition, women with no education are more likely to be undernourished, which could contribute to a higher risk of spontaneous abortion and stillbirth.

Next, the links between successive indicators are examined by level of education at the country level.

\section{Effect of contraceptive use on fertility}

Figure 10 plots the relationship between fertility and contraceptive prevalence, with each of the 30 sub-Saharan countries contributing three points, one for each level of education. The OLS regression lines fitted through these sets of points differ for two reasons. First, as the education level rises, the data points for each country (and the regression lines) shift to lower fertility and higher prevalence, as expected. Second, at a given level of contraceptive use, more education is associated with lower fertility. This result is most likely due to later marriage, more effective use of contraception, and greater reliance on abortion among better-educated women.

\section{Effect of demand for contraception on use of contraception}

Figure 11 plots the relationship between contraceptive prevalence and demand by level of education for 30 countries. With rising levels of education, the expected shift to higher levels of use and demand is evident. In addition, at a given level of demand, contraceptive use increases as the level of education rises. This finding is consistent with the conclusions from earlier studies that better-educated women have greater knowledge of contraception, higher autonomy to make decisions regarding their reproductive lives, better access to services, and greater motivation to implement demand (Jejeebhoy 1995; National Research Council 1999).

\section{Effect of desired family size on the demand for contraception}

The expected inverse association between desired family size and demand for contraception exists for each education level (see Figure 12). The main finding of interest is that at a given level of desired family size, demand for contraception increases as the education level rises. A possible explanation for this result is that women with higher education have shorter periods of breastfeeding, thus requiring more contraception to maintain adequate birth spacing. Demand for limiting may also be higher because both the cost of unwanted births and obstacles to implementing preferences rise with level of education.

\section{Unmet need for contraception and unwanted fertility}

As shown in Figure 13, the inverted U-shaped relationship between unmet need and demand for contraception is evident at each education level. At a given level of demand, higher education is associated with lower unmet need. The explanation is the same as for higher use at a given level of demand: more highly educated women have greater autonomy, more knowledge, 
better access to services, and higher motivation to avoid unintended pregnancy. The differences between education-specific proportions of demand satisfied presented in Figure 14 are explained by the same factors.

Finally, unwanted fertility exhibits a weak inverted U-shaped pattern for all three education levels (see Figure 15). As expected, unwanted fertility is lowest in the highest education group because women in this group have higher levels of satisfied demand and lower unmet need for contraception.

\section{CONCLUSION}

Reproductive indicators differ widely among countries in sub-Saharan Africa, but the indicators have predictable associations. In countries with the highest fertility, demand for children is high and demand for and use of contraception is low. Conversely, in countries in which fertility has declined, desired family size is lower and both demand for contraception and women's implementation of this demand are relatively high. These findings are consistent with the conventional wisdom on the determinants of fertility.

Country-specific levels of unmet need for contraception and unwanted fertility show a less obvious inverted-U shape. Unmet need and unwanted fertility tend to rise in the early phases of the transition as a rising demand for contraception is left substantially unsatisfied; they peak in mid-transition and then decline in the later stages of the transition (despite still rising demand) as the proportion of this demand that is satisfied grows.

Differences by level of education within countries are also generally consistent with the conventional wisdom: education levels are positively associated with demand for and use of contraception and negatively associated with fertility and desired family size.

In addition, there are differences by level of education in the relationships between indicators. As education rises, fertility is lower at a given level of contraceptive use, contraceptive use is higher at a given level of demand, and demand is higher at a given level of desired family size. The most plausible explanations for these shifting relationships are that better-educated women marry later and less often, use contraception more effectively, have more knowledge about and access to contraception, have greater autonomy in reproductive decisionmaking, and are more motivated to implement demand because of the higher opportunity costs of unintended childbearing.

\section{Notes}

1 Mauritania 2000 and Eritrea 2002 are excluded from this analysis because the DHS data tapes were not available.

2 Fitted line represents a second-order polynomial with intercept set to zero.

3 Country estimates by education are age standardized. 


\section{REFERENCES}

Bankole, Akinrinola and Charles F. Westoff. 1995. "Childbearing attitudes and intentions," Demographic and Health Surveys, Comparative Studies No. 17. Calverton, MD: Macro International.

Bongaarts, John. 1997. "Trends in unwanted childbearing in the developing world," Studies in Family Planning 28(4): 267-277.

Bongaarts, John and Robert G. Potter. 1983. Fertility, Biology, and Behavior: An Analysis of the Proximate Determinants. New York: Academic Press.

Caldwell, John C. 1982. Theory of Fertility Decline. London: Academic Press.

Casterline, John B. and Steven W. Sinding. 2000. "Unmet need for family planning in developing countries and implications for population policy," Population and Development Review 26(4): 691-723.

Castro Martín, T. and F. Juárez.1995. "The impact of women's education on fertility in Latin America: Searching for explanations," International Family Planning Perspectives 21(2):52-57.

Cleland, John and Germán Rodríguez. 1988. "The effect of parental education on marital fertility in developing countries," Population Studies 42(3): 419-442.

Cochrane, Susan Hill. 1979. Fertility and Education: What Do We Really Know? Baltimore, MD: Johns Hopkins University Press.

Jeffery, Roger and Alaka M. Basu (eds.). 1996. Girls' Schooling, Women's Autonomy and Fertility Change in South Asia. New Delhi: Sage Publications.

Jejeebhoy, Shireen J. 1995. Women's Education, Autonomy and Reproductive Behaviour: Experience from Developing Countries. Oxford: Clarendon Press.

Merrick, Thomas. 2001. "Population and poverty: A review of reviews," in Nancy Birdsall, Allen C. Kelley, and Steven W. Sinding (eds.), Population Matters: Demographic Change, Economic Growth, and Poverty in the Developing World. New York: Oxford University Press, pp. 201-212.

National Research Council. 1999. Critical Perspectives on Schooling and Fertility in the Developing World, Caroline H. Bledsoe, John B. Casterline, Jennifer A. Johnson-Kuhn, and John G. Haaga (eds.). Washington, DC: National Academy Press.

Rodriguez, G., and R. Aravena.1991. "Socioeconomic factors and the transition to low fertility in less developed countries: A comparative analysis," paper presented at the Demographic and Health Surveys World Conference, Washington DC, August 5-7. 
Ross, John, John Stover, and Demi Adelaja. 2005. Profiles for Family Planning and Reproductive Health Programs: 116 Countries. $2^{\text {nd }}$ edition. Glastonbury, CT: The Futures Group.

Rutstein, Shea. 2002. "Fertility levels, trends and differentials: 1995-1999," Demographic and Health Survey Comparative Reports No. 3. Calverton, MD: Macro International, Inc.

Singh, S. and J. Casterline. 1985. "Socioeconomic determinants," pp. 199-222 in J. Cleland and J. Hobcraft (eds.), Reproductive Change in Developing Countries. Oxford: Oxford University Press.

United Nations. 1987. "Fertility behavior in the context of development: Evidence from the World Fertility Surveys," Population Studies no. 100. New York: United Nations.

-1995. Women's Education and Fertility Behavior: Recent Evidence from the Demographic and Health Surveys. New York: United Nations.

- 2001. Levels and Trends of Contraceptive Use as Assessed in 1998. New York: United Nations.

— 2007. World Population Prospects: The 2006 Revision. New York: United Nations.

Westoff, Charles F. 2001. Unmet Need at the End of the Century. DHS Comparative Reports No. 1. Calverton, Maryland: ORC Macro. 
Table 1 Estimates of total fertility rate, current use of and demand for contraception among married women, and desired family size (ages 20-29) for 30 countries in sub-Saharan Africa

\begin{tabular}{|c|c|c|c|c|}
\hline & $\begin{array}{c}\text { Total fertility } \\
\text { rate } \\
\text { (births/woman) }\end{array}$ & $\begin{array}{c}\text { Contraceptive } \\
\text { prevalence } \\
(\%) \\
\end{array}$ & $\begin{array}{c}\text { Demand for } \\
\text { contraception } \\
(\%) \\
\end{array}$ & $\begin{array}{c}\text { Desired } \\
\text { family size } \\
\text { (births/woman) } \\
\end{array}$ \\
\hline Benin 2006 & 5.7 & 17.0 & 47.0 & 4.7 \\
\hline Burkina Faso 2003 & 5.9 & 13.8 & 42.6 & 5.3 \\
\hline Cameroon 2004 & 5.0 & 26.0 & 46.2 & 5.4 \\
\hline Chad 2004 & 6.3 & 2.8 & 23.5 & 8.6 \\
\hline Congo (Braz) 2005 & 4.8 & 44.3 & 60.5 & 4.9 \\
\hline Congo Dem. Rep. 2007 & 6.3 & 20.6 & 45.0 & 6.2 \\
\hline Côte d'Ivoire 1998/99 & 5.2 & 15.0 & 42.7 & 4.8 \\
\hline Ethiopia 2005 & 5.4 & 14.7 & 48.7 & 4.4 \\
\hline Gabon 2000 & 4.2 & 32.7 & 60.7 & 4.6 \\
\hline Ghana 2003 & 4.4 & 25.2 & 59.2 & 4.1 \\
\hline Guinea 2005 & 5.7 & 9.1 & 30.4 & 5.3 \\
\hline Kenya 2003 & 4.9 & 39.3 & 65.9 & 3.6 \\
\hline Lesotho 2004 & 3.5 & 37.3 & 68.3 & 2.8 \\
\hline Liberia 2007 & 5.2 & 11.5 & 47.2 & 4.6 \\
\hline Madagascar 2003/04 & 5.2 & 27.1 & 50.8 & 4.5 \\
\hline Malawi 2004 & 6.0 & 32.5 & 61.8 & 3.8 \\
\hline Mali 2006 & 6.6 & 8.2 & 39.5 & 6.1 \\
\hline Mozambique 2003 & 5.5 & 25.5 & 43.9 & 4.9 \\
\hline Namibia 2000 & 4.2 & 43.7 & 65.9 & 3.0 \\
\hline Niger 2006 & 7.0 & 11.2 & 27.1 & 8.5 \\
\hline Nigeria 2003 & 5.7 & 12.6 & 29.5 & 6.4 \\
\hline Rwanda 2005 & 6.1 & 17.4 & 55.3 & 4.1 \\
\hline Senegal 2005 & 5.3 & 11.8 & 43.5 & 5.3 \\
\hline South Africa 1998 & 2.9 & 56.3 & 71.6 & 2.6 \\
\hline Swaziland 2006 & 3.9 & 50.6 & 74.7 & 2.3 \\
\hline Tanzania 2004 & 5.7 & 26.4 & 49.5 & 4.7 \\
\hline Togo 1998 & 5.2 & 23.5 & 55.8 & 4.3 \\
\hline Uganda 2006 & 6.7 & 23.7 & 64.3 & 4.6 \\
\hline Zambia 2001/02 & 5.9 & 34.2 & 61.7 & 4.4 \\
\hline Zimbabwe 2005/06 & 3.8 & 60.2 & 73.7 & 3.4 \\
\hline
\end{tabular}

Source: DHS 
Figure 1: Analytic framework for the determinants of fertility

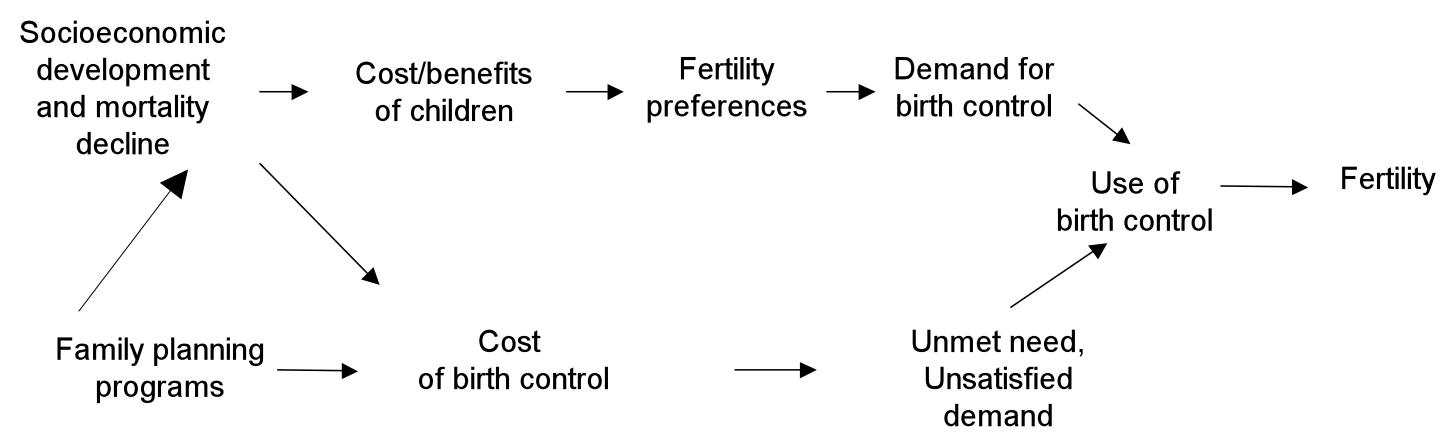

Fig 2: Relationship between total fertility rate and contraceptive prevalence

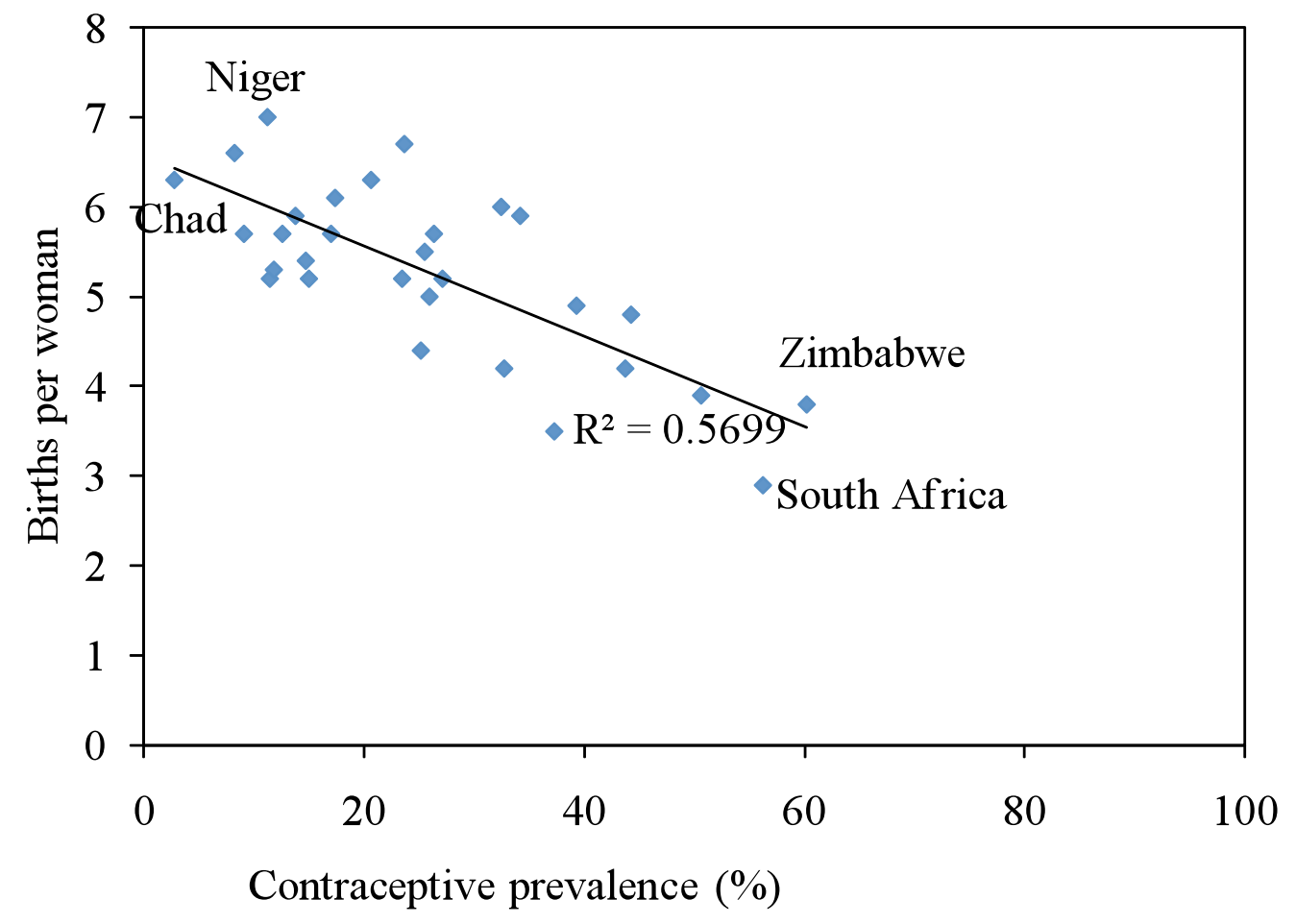

Source: DHS 
Fig 3: Relationship between contraceptive prevalence and demand for contraception

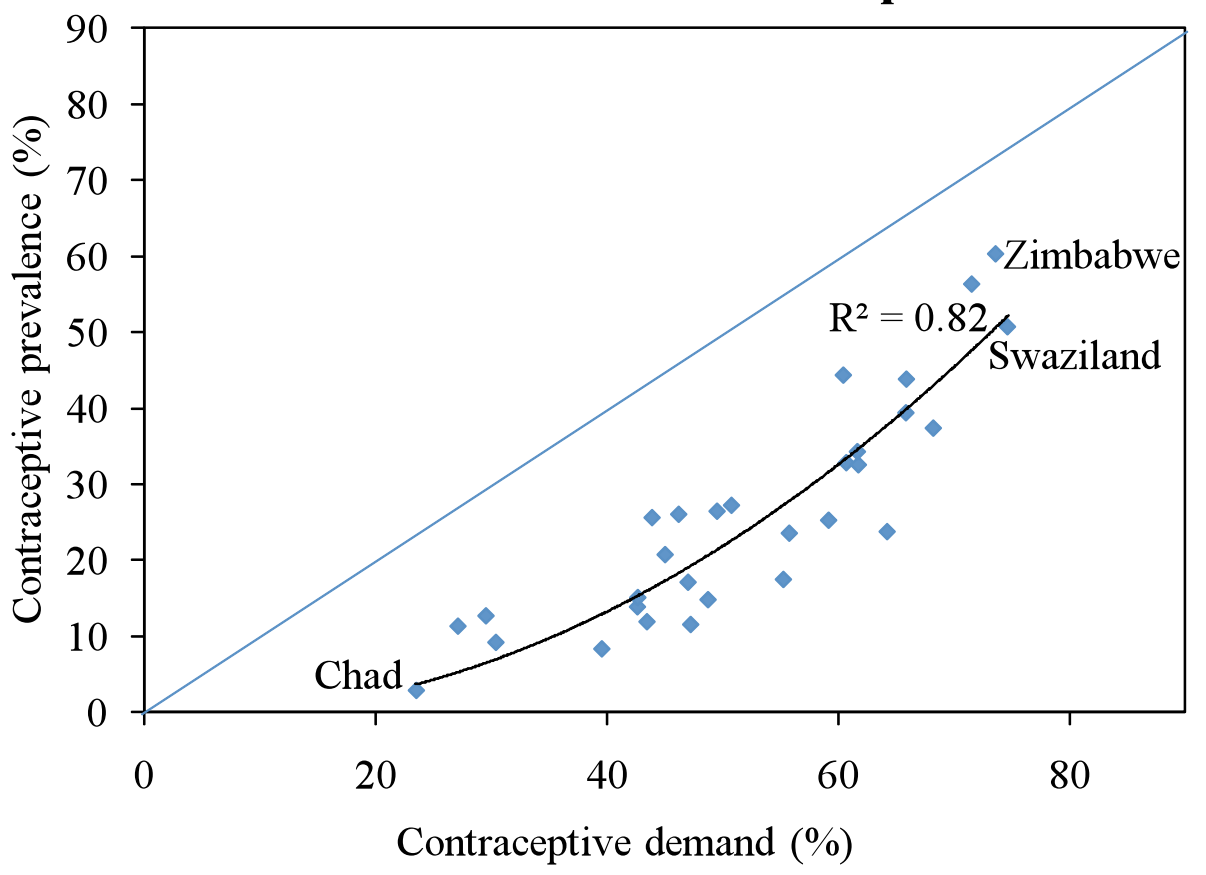

Source: DHS

Fig 4: Relationship between contraceptive demand and desired family size

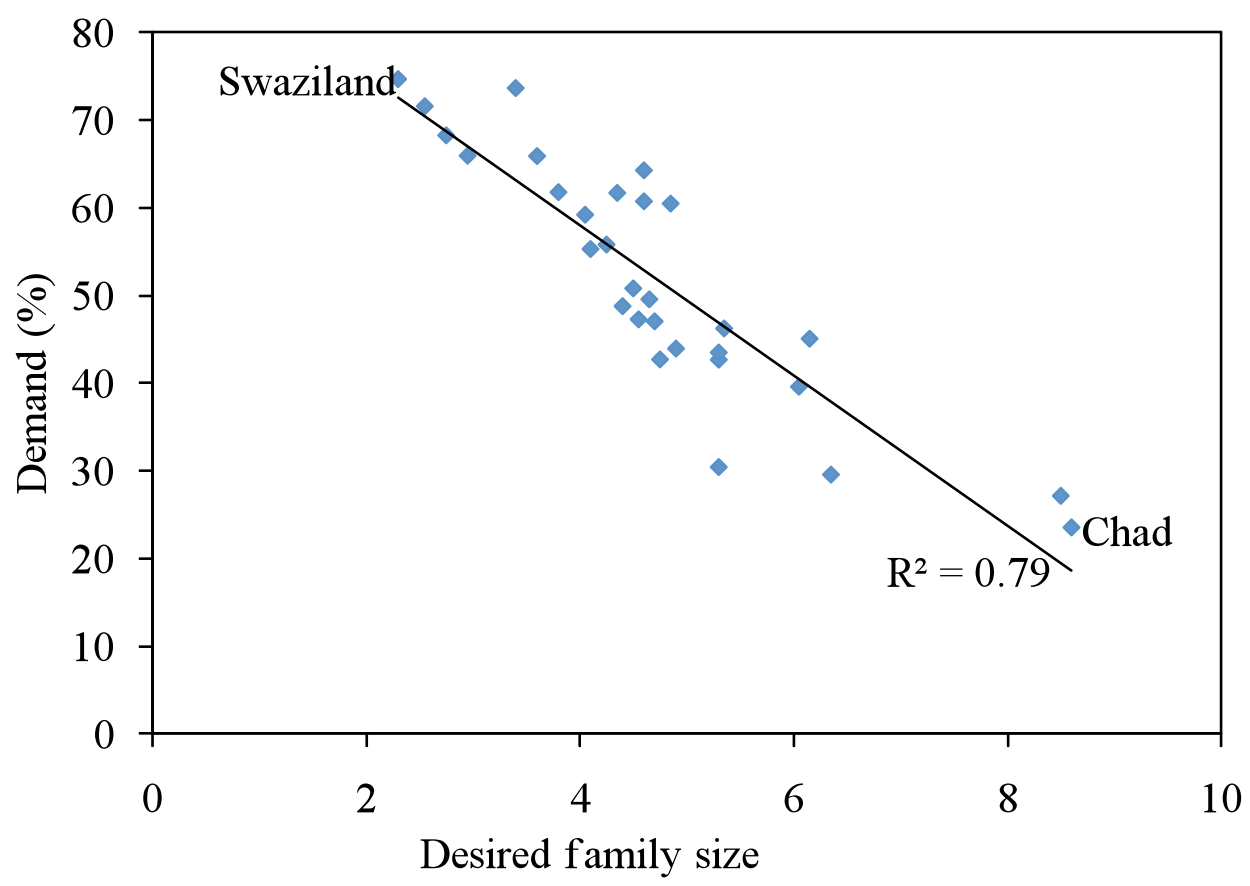

Source: DHS 
Fig 5: Relationship between unmet need and demand for contraception

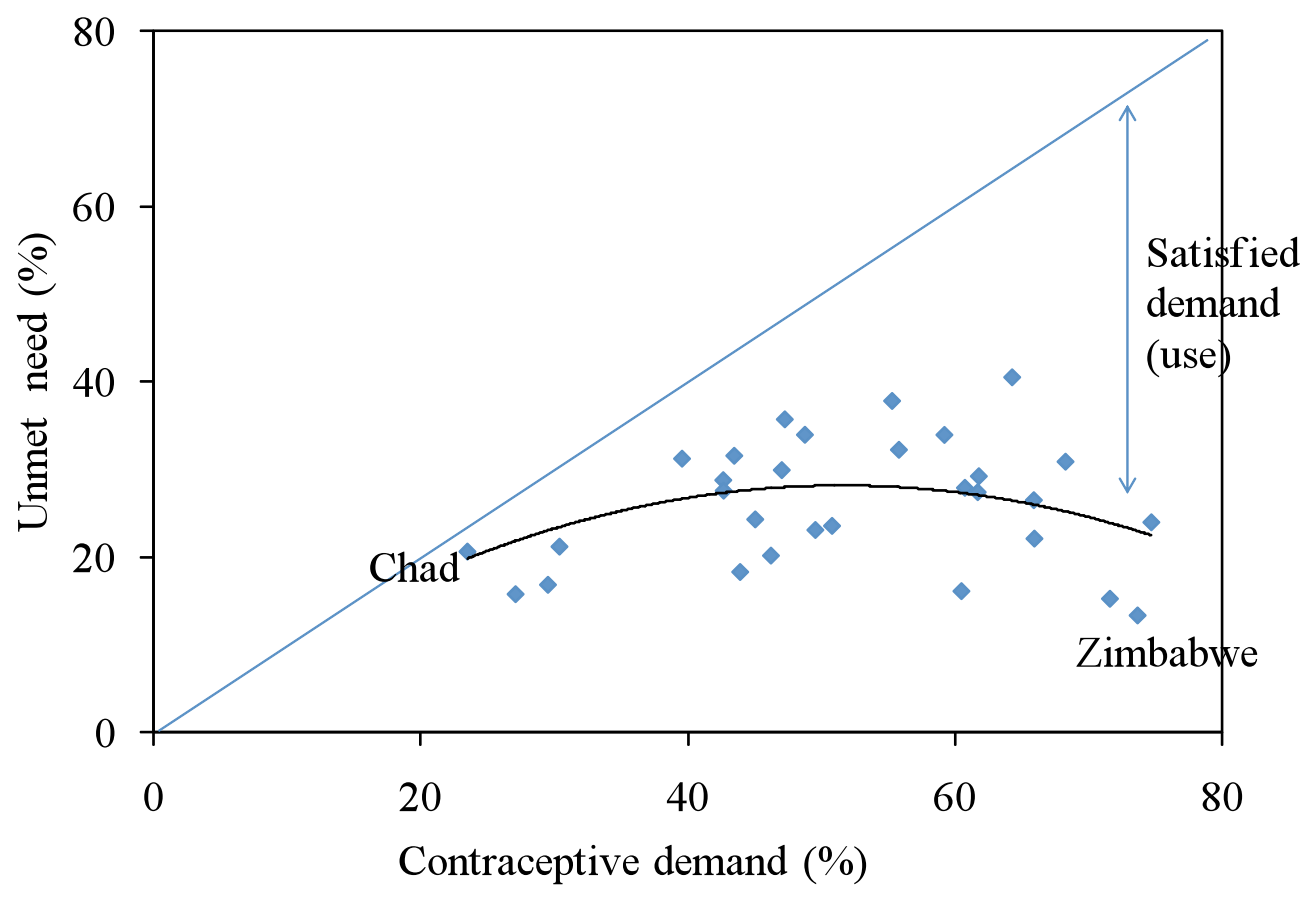

Source: DHS

Fig 6: Relationship between percent satisfied and demand for contraception

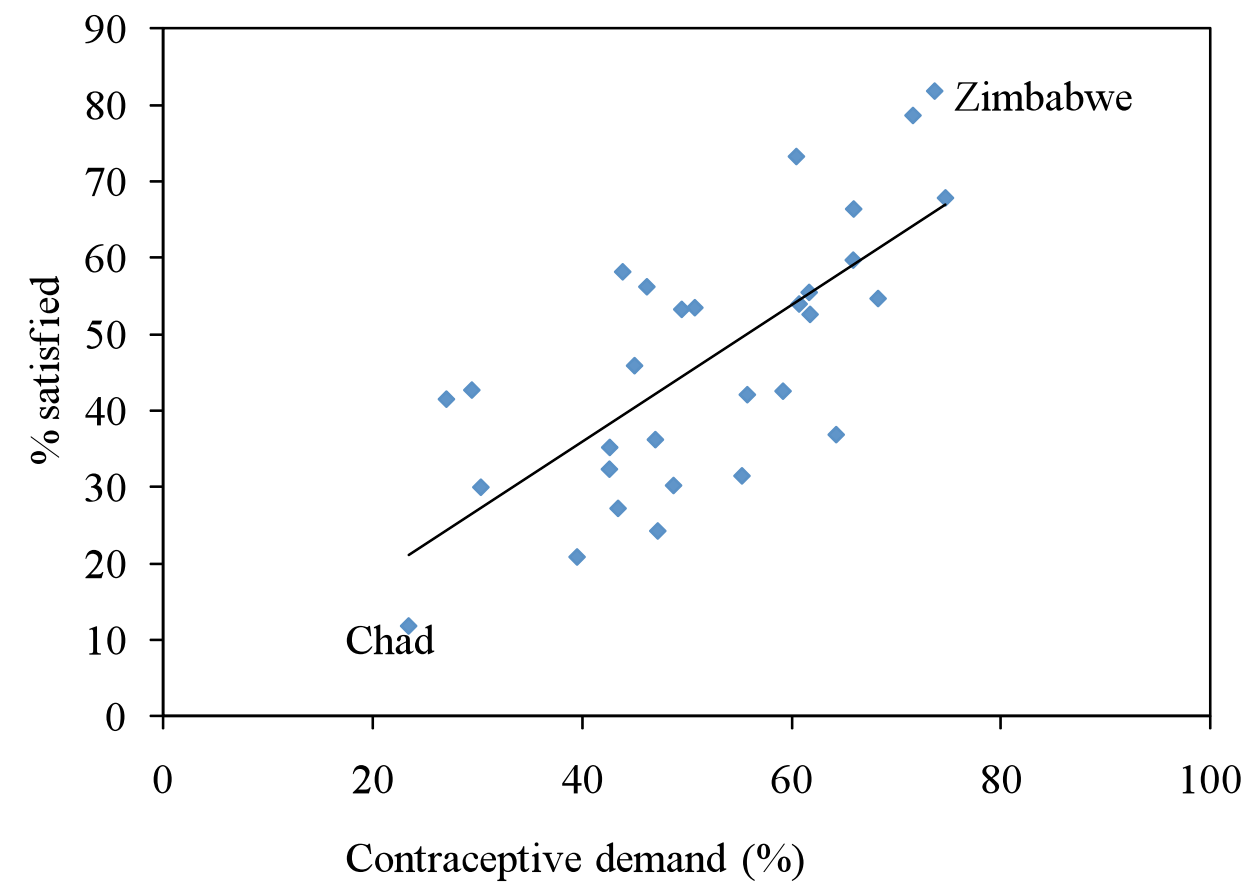

Source: DHS 
Fig 7: Relationship between unwanted fertility and total fertility rate

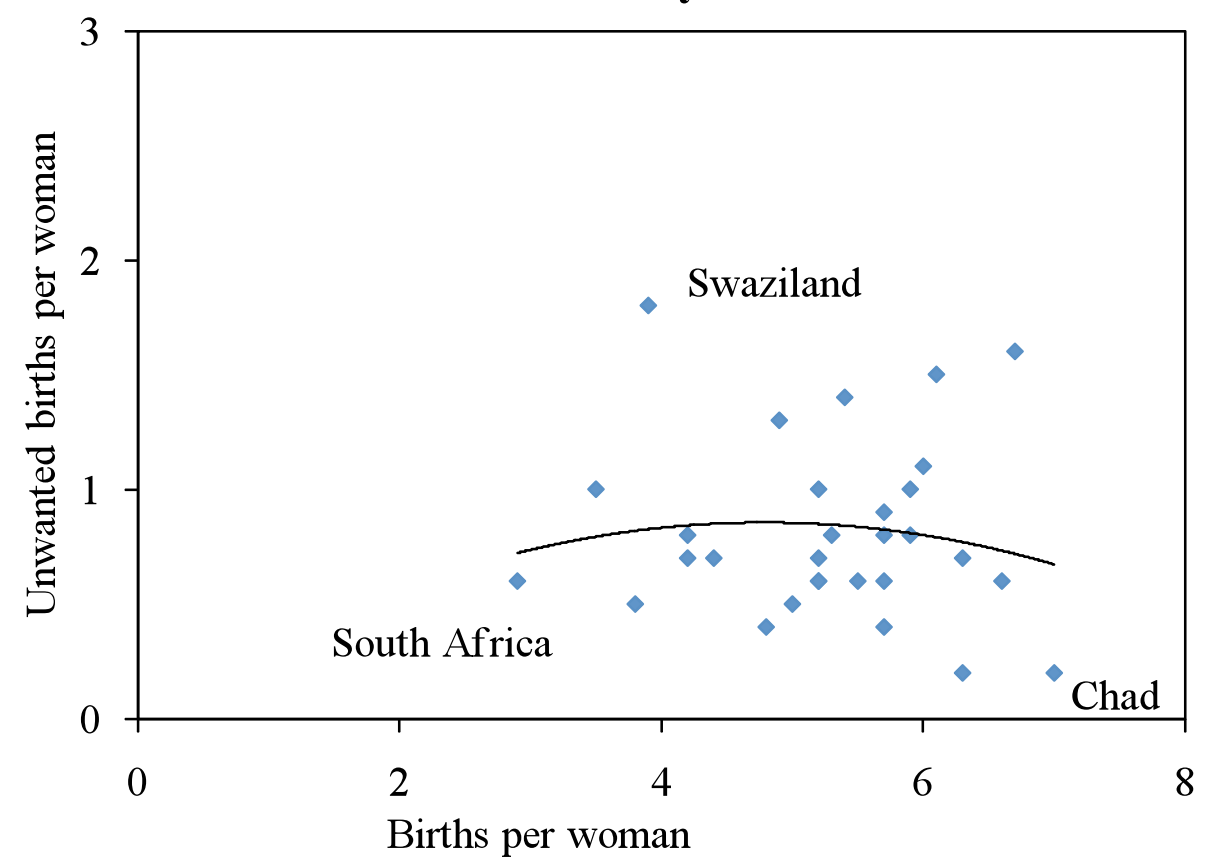

Source: DHS

Fig 8: Total fertility rate and desired family size by level of education, average of $\mathbf{3 0}$ countries

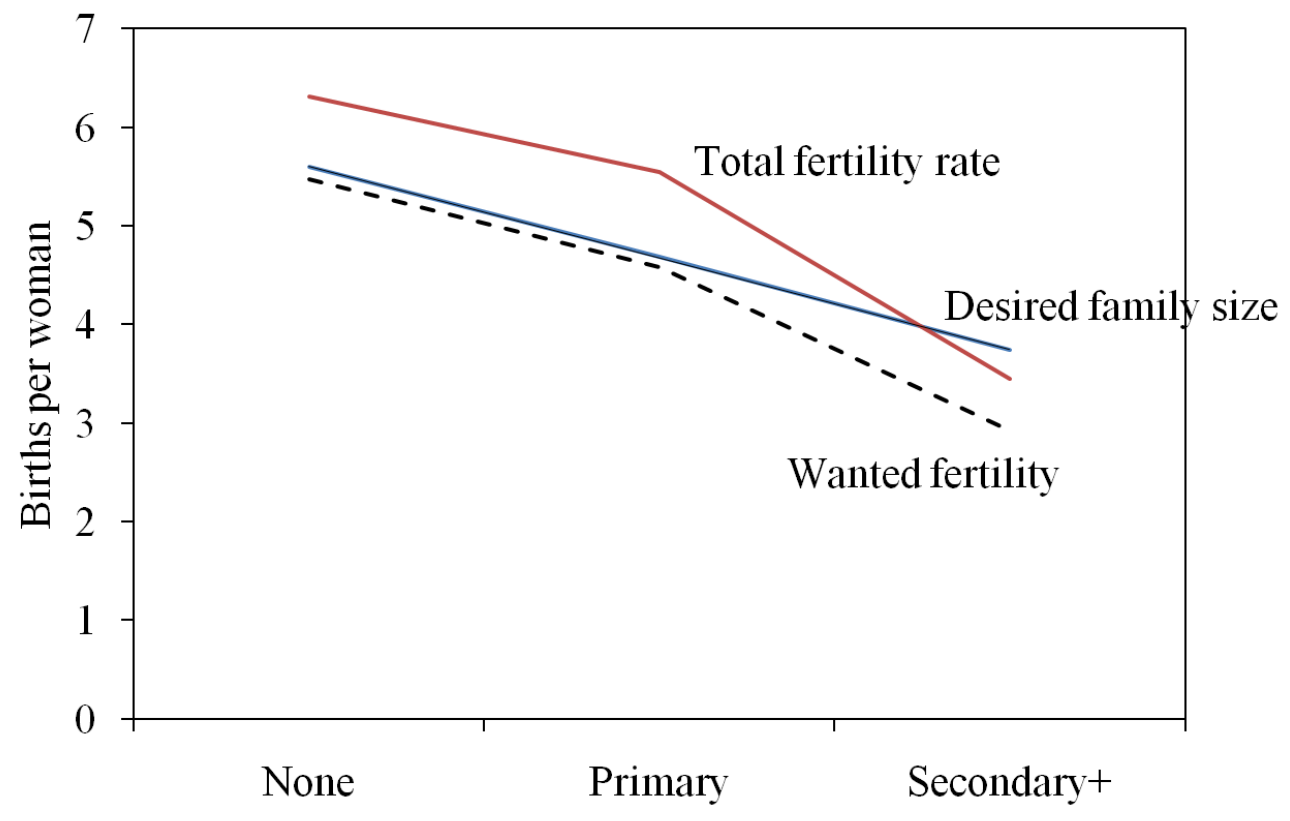


Fig. 9: Demand for and use of contraception by level of education, average of 30 countries

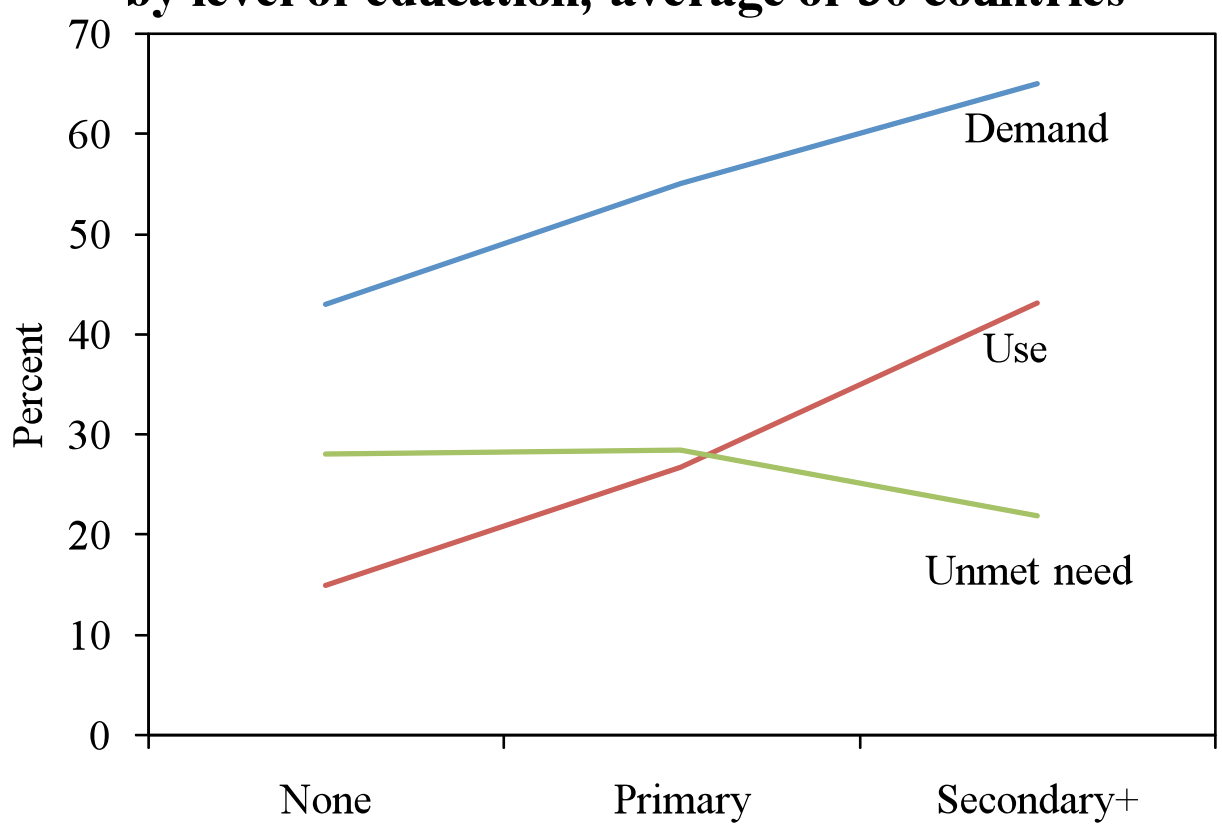

Source: DHS

Fig. 10: Relationship between total fertility rate and contraceptive prevalence by level of education

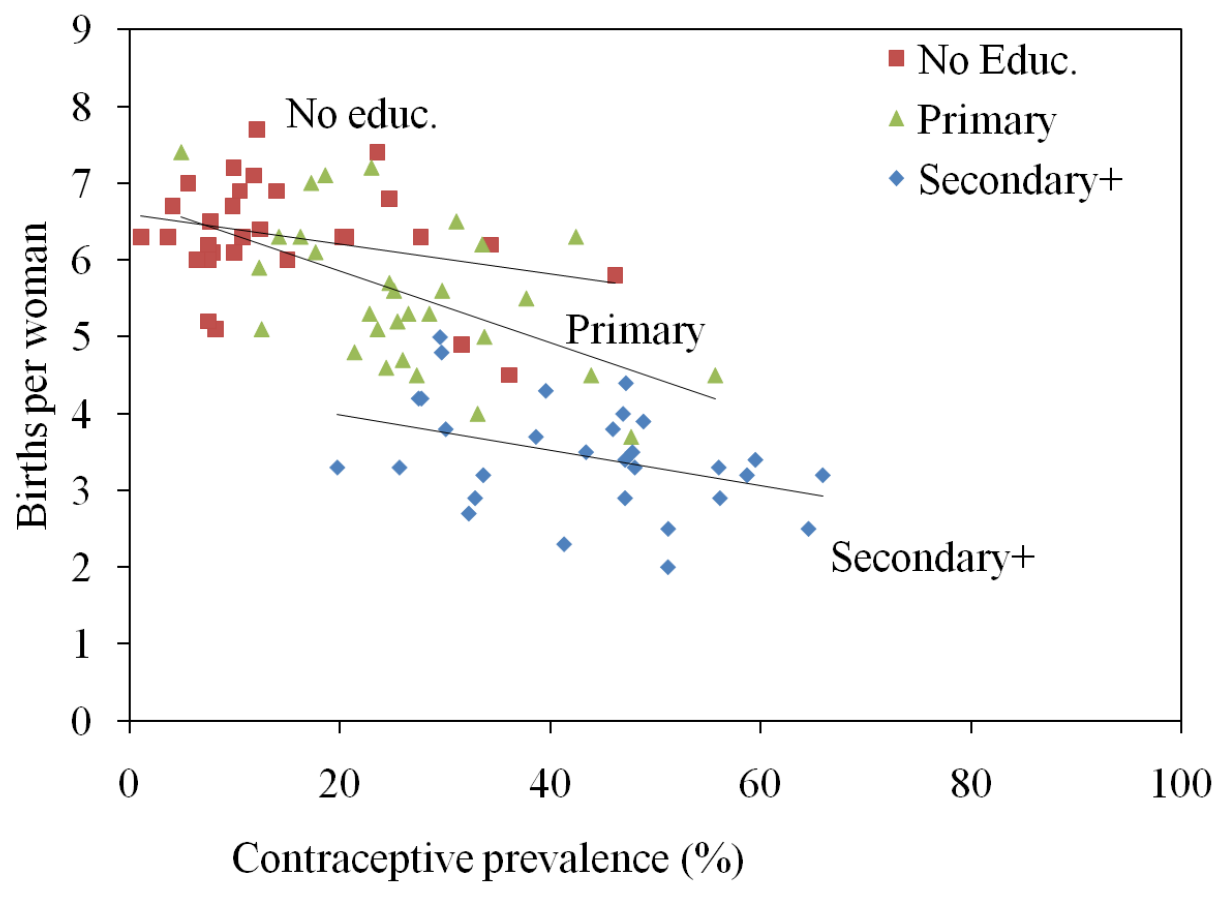


Fig. 11: Relationship between contraceptive prevalence and demand by level of education

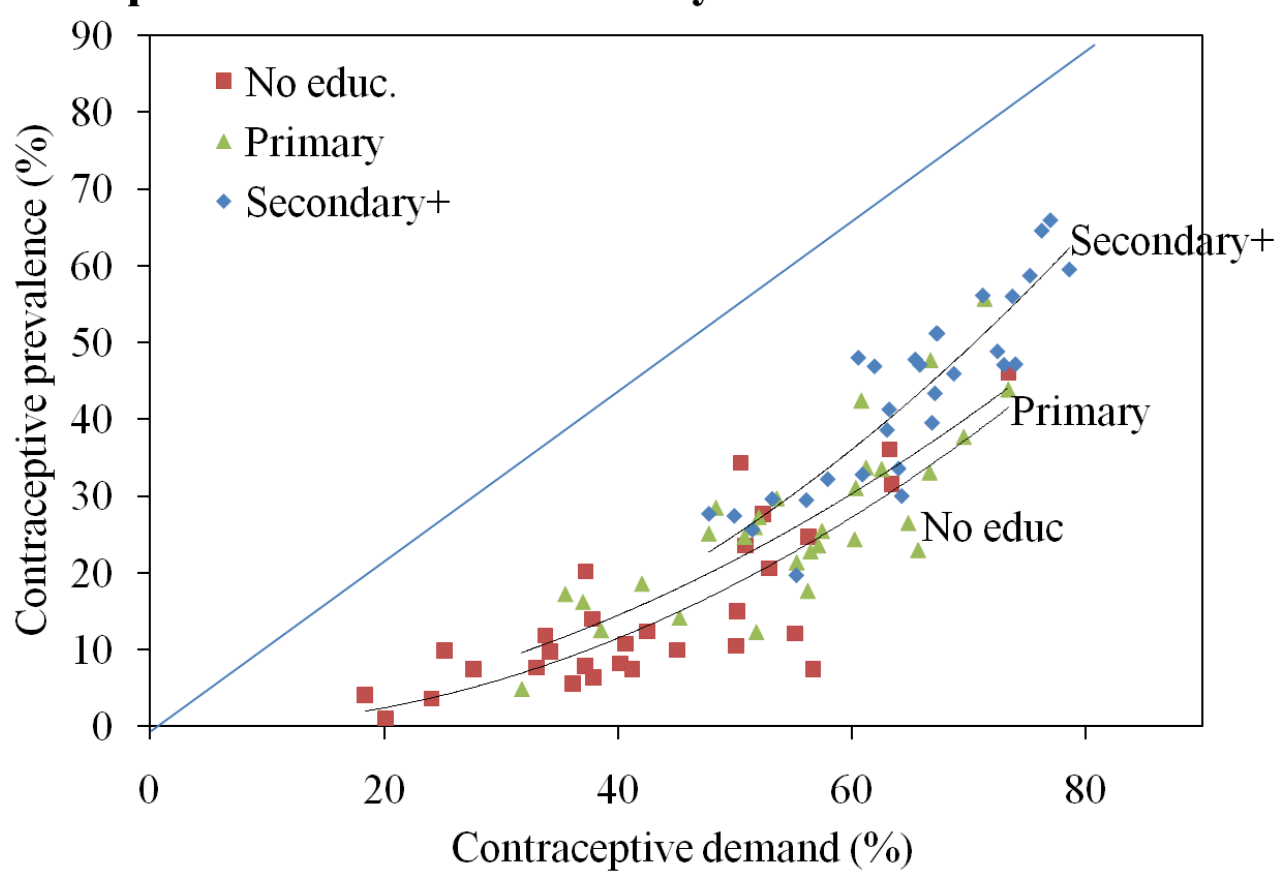

Source: DHS

Fig. 12: Relationship between demand for contraception and desired family size by level of education

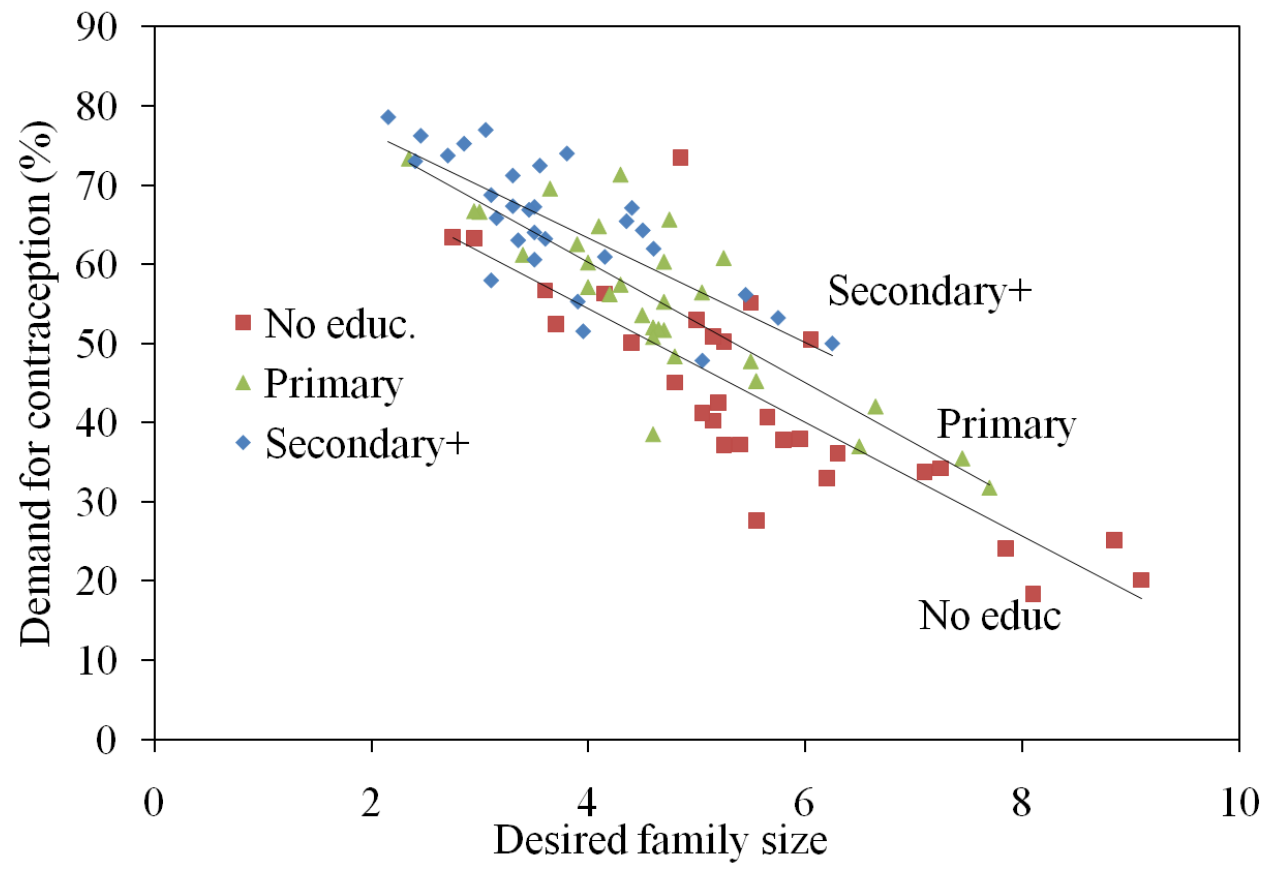

Source: DHS 
Fig. 13: Relationship between unmet need and demand for contraception by level of education

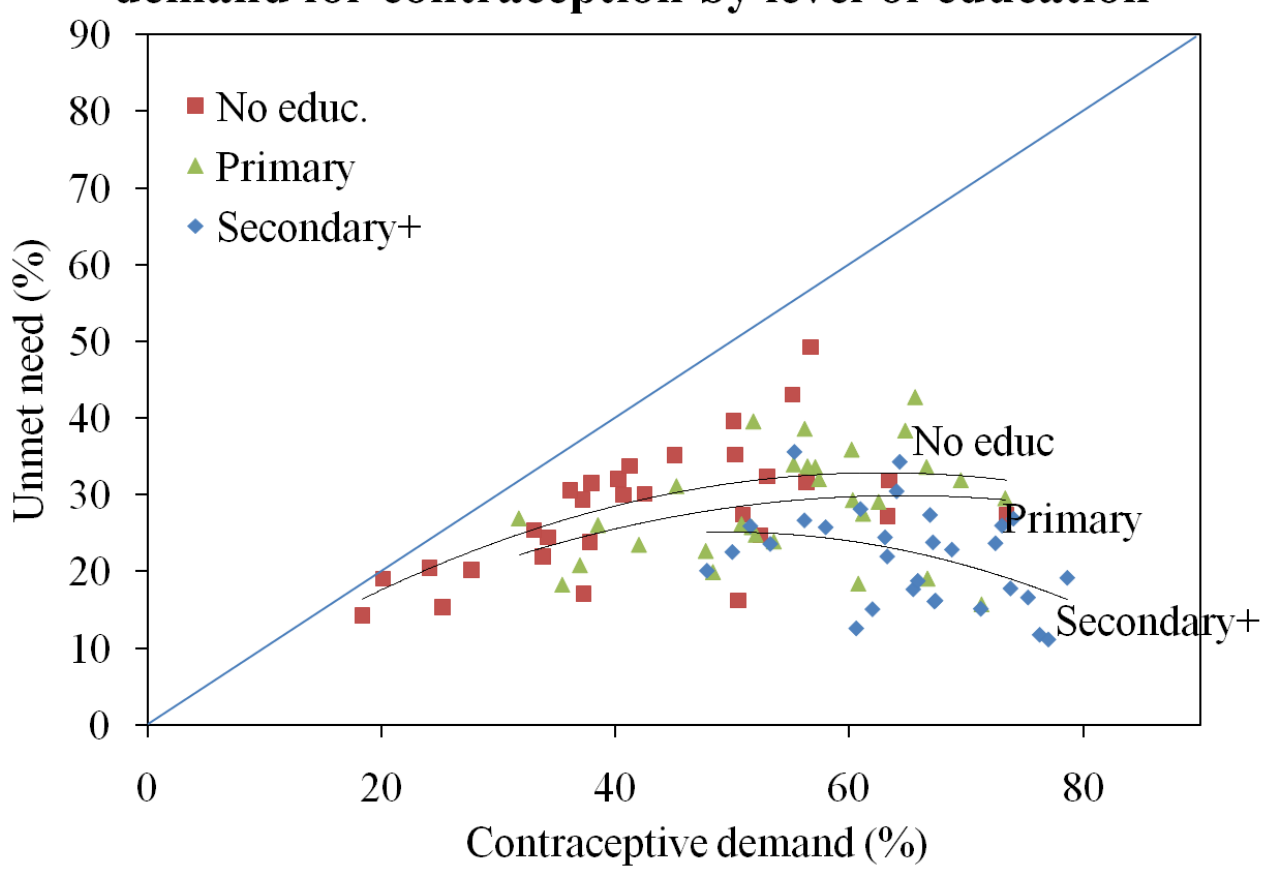

Fig. 14: Relationship between percent satisfied and demand for contraception by level of education

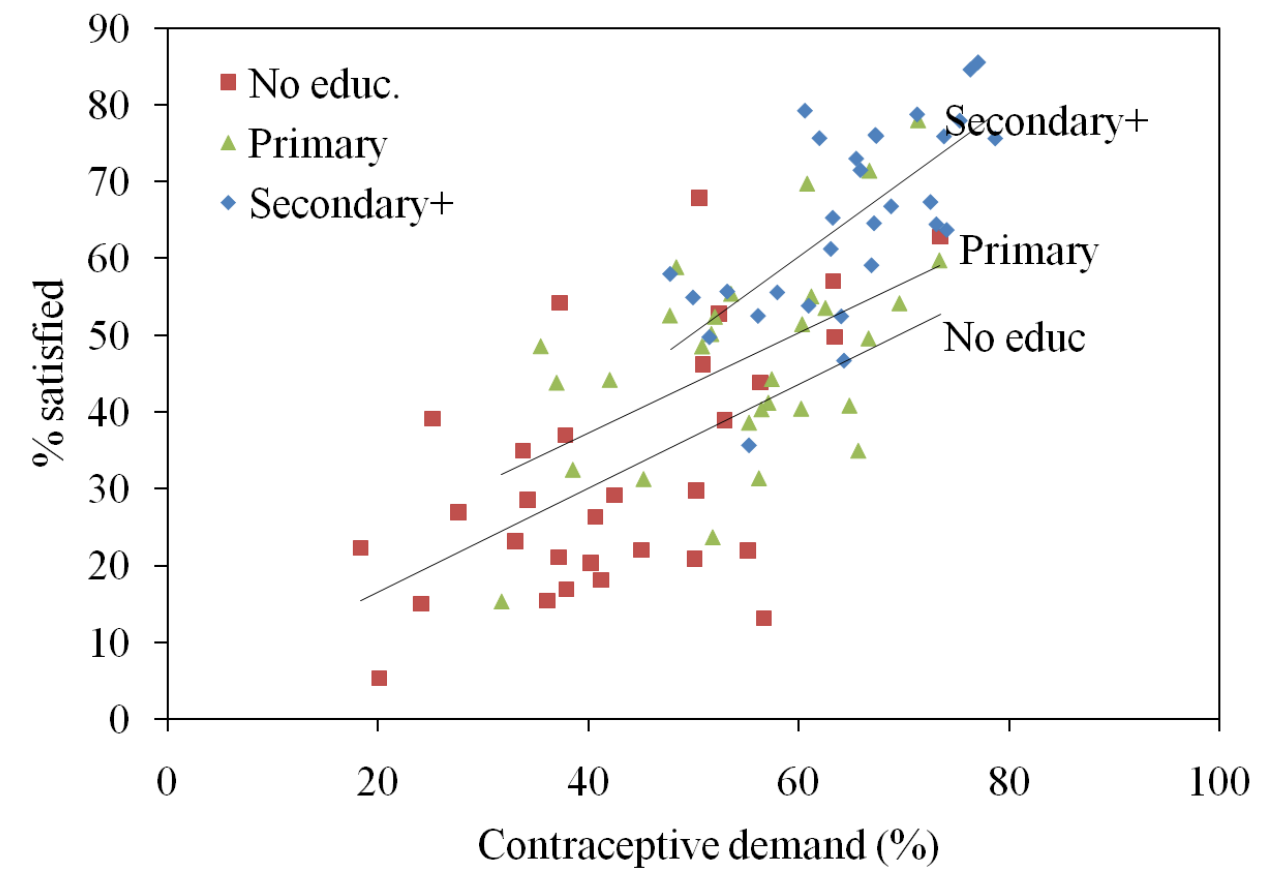

Source: DHS 
Fig. 15: Relationship between unwanted fertility and total fertility rate by level of education

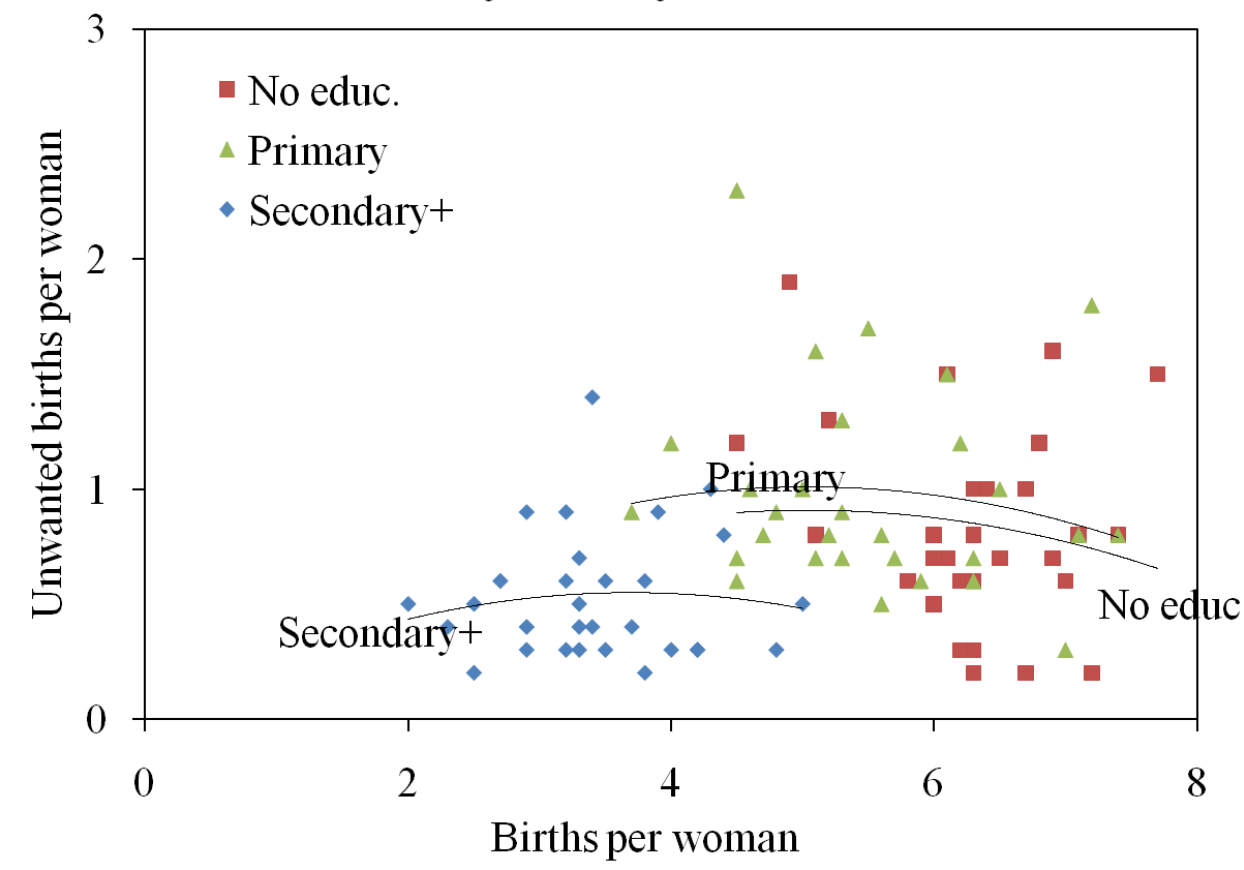




\section{Recent Poverty, Gender, and Youth Working Papers}

Working papers are distributed electronically. When a new paper is published, subscribers are notified by e-mail and a link to the paper is provided.

To subscribe to the Poverty, Gender, and Youth working paper e-mail notification list, please send your request to pgywp@popcouncil.org.

PDFs of working papers are available at www.popcouncil.org/publications/wp/index.html

2010

20 John Bongaarts, “The causes of educational differences in fertility in sub-Saharan Africa.”

19 Ashish Bajracharya and Sajeda Amin, "Poverty, marriage timing, and transitions to adulthood in Nepal: A longitudinal analysis using the Nepal Living Standards Survey.”

2009

18 Sajeda Amin and Bussarawan Teerawichitchainan, "Ethnic fertility differentials in Vietnam and their proximate determinants.”

17 Sajeda Amin and S. Chandrasekhar, "Looking beyond universal primary education: Gender differences in time use among children in rural Bangladesh.”

16 John Bongaarts, François Pelletier, and Patrick Gerland, "Global trends in AIDS mortality.”

15 Bussarawan Teerawichitchainan and Sajeda Amin, "The role of abortion in the last stage of fertility decline in Vietnam.”

14 Cynthia B. Lloyd and Paul C. Hewett, "Educational inequalities in the midst of persistent poverty: Diversity across Africa in educational outcomes."
13 Wendy Baldwin and Judith Diers, "Demographic data for development in sub-Saharan Africa.”

2008

12 Sajeda Amin and Lopita Huq, "Marriage considerations in sending girls to school in Bangladesh: Some qualitative evidence.”

11 S. Chandrasekhar and Abhiroop Mukhopadhyay, "Multiple dimensions of urban well-being: Evidence from India”

10 Sajeda Amin and Luciana Suran, "Terms of marriage and time-use patterns of young wives: Evidence from rural Bangladesh.”

9 John Bongaarts, Thomas Buettner, Gerhard Heilig, and François Pelletier, "Has the HIV epidemic peaked?”

8 Barbara S. Mensch, Paul C. Hewett, Richard Gregory, and Stephane Helleringer, "Sexual behavior and STI/HIV status among adolescents in rural Malawi: An evaluation of the effect of interview mode on reporting."

7 John Bongaarts, "Fertility transitions in developing countries: Progress or stagnation?” 